\title{
ACTIVANDO ${ }^{1}$ EL MUNDO SIMBÓLICO PARA ENFRENTAR LA EMIGRACIÓN
}

\author{
ACTIVATING THE SIMBOLIC WORLD TO CULTURALLY \\ HANDLE EMIGRATION
}

\author{
Ana Bella Pérez Castro ${ }^{1}$
}

\begin{abstract}
La emigración es un fenómeno social que hoy día en México ha cobrado dimensiones alarmantes. De todos los estados de la República Mexicana, día con día salen hombres y mujeres jóvenes hacia los Estados Unidos en busca de trabajo. Sin embargo, dejar la familia y el poblado de origen no es fácil ni para los que se van ni para los que se quedan. En este sentido, cabe preguntarse ¿cómo enfrentan la emigración los que se van y cómo los que se quedan? Preguntas a las que me interesa dar respuesta tomando el caso de los habitantes indígenas de la región Huaxteca, México. Partiré del concepto de formas simbólicas utilizado por John B. Thompson, con la finalidad de dar cuenta de los usos sociales de apropiación y transformación que las poblaciones afectadas por la emigración hacen de éstas; para ello, intentaré identificar los diversos modos en que opera la ideología y algunas de las estrategias típicas de la construcción simbólica.

En el trabajo se da cuenta de los diversos enfoques utilizados para explicar la emigración y se aborda ya en el caso específico de la región Huaxteca, el contexto social en que se da, la diversidad de aspectos socioculturales relacionados con tal proceso y la forma en que simbólicamente la población la enfrenta.
\end{abstract}

Palabras claves: formas simbólicas, emigración, creencias, estrategias, organización social.

Nowadays, emigration in Mexico is a social phenomenon reaching alarming proportions. Everyday, from every State in the country, young men and women make their way toward the United States in search of a job. Nevertheless, leaving behind family and hometown is not an easy thing, for those leaving, nor for those that stay. Thus, it is plausible to ask: How do the ones who leave and those who stay behind deal with emigration? I am interested in answering this question through the case of the people of the Huaxteca region, in Mexico. I do so by applying the concept of symbolic forms proposed by John B. Thompson in order to emphasize the social uses of appropriation and transformation that the communities affected by emigration grant to these symbolic forms. In order to accomplishing this, I identify the different ways ideology operates as well as some of the typical strategies of symbolic construction.

In this work, I refer to different approaches in order to explain migration. Also I refer to these approaches to explain specific aspects -in the case of Huaxteca region-such as the social context as well as the diversity of sociocultural dimensions related to migration, and the symbolic ways the population deals with it.

Key words: Symbolic forms, emigration, beliefs, strategies, social organization.

El tema de la migración ha sido una cuestión recurrente en las ciencias sociales en México. En las investigaciones antropológicas el tema cobra importancia a partir de la segunda década del siglo pasado, cuando Oscar Lewis realizó su investigación sobre cien familias del poblado de Tepoztlán (estado de Morelos) que emigraron, en diferentes períodos, a la ciudad de México. En tal estudio, el autor intentó mostrar que los emigrantes tendían a perpetuar una "cultura de la pobreza". A partir de su trabajo, las investigaciones sobre el tema se diversificaron y se buscaron otras explicaciones para dar cuenta del fenómeno migratorio. El funcionalismo, la teoría de la dependencia, el enfoque "histórico-estructural" y el marxismo fueron algunos de los principales ejes sobre los que giraron las investigaciones destacando, entre otros aspectos, el peso que tenía el sistema económico nacional e internacional en la explicación de las movilizaciones humanas y la relación entre migración y pertenencia ${ }^{3}$.

Para la última década del siglo XX, el tema más que agotarse se abre a nuevas miradas. Surgen nuevas teorías y paradigmas para dar cuenta de este

$1 \quad$ IIA-Universidad Nacional Autónoma de México. bella@ servidor.unam.mx 
fenómeno y se van privilegiando ciertos aspectos relacionados con el movimiento de gente ${ }^{4}$; movimiento que no se detiene, que no deja de asombrarnos y plantearnos interrogantes que necesitan de nuevas formas de construir el conocimiento, de “... afrontar con nuevas herramientas teóricas y metodológicas el reto que plantea un fenómeno que, sin ser novedoso, sí manifiesta importantes particularidades históricas..." (Blanco 2006:11). En efecto, la circulación de hombres y mujeres, lejos de ser tema del pasado, es actualidad y futuro, y lo es en la medida que, como señala Cristina Blanco

el crecimiento del volumen de migrantes, el número de países involucrados en las redes migratorias internacionales, la diversificación de los tipos de migraciones (o motivos para desplazarse), así como las consecuencias sociales, económicas y culturales, son las principales características de una movilidad humana sin precedentes (Blanco 2006:12).

En este sentido, se habla del transnacionalismo como un fenómeno que da pie a cuestionamientos que giran sobre la relación que establecen los emigrantes entre la comunidad de origen y la de destino $^{5}$. La gestión de las migraciones y sus consecuencias es otro de los nuevos temas relacionados con la migración. La presencia de los emigrantes en diversos contextos y momentos históricos ha llevado a que el tema no sólo sea motivo de investigación, sino que los países directamente relacionados con este fenómeno han coincidido en la necesidad de abordarlo mediante políticas y acuerdos regionales globales que reúna a los países expulsores y receptores en la búsqueda de un beneficio común que sugiere la idea de gestión.

Sin la intención de hacer un recuento de autores, teorías y paradigmas que representan las nuevas formas de pensamiento para dar cuenta de la migración, considero importante mencionar algunos casos relevantes para justificar la mirada con la que, en este trabajo, me acerco a tal fenómeno.

\section{Migración, Cultura y Simbolismo}

Me interesa destacar que en esta nueva fase del capitalismo llamada globalización, las investigaciones sobre el fenómeno de la migración se enfocan y reflexionan sobre lo efectos que tiene sobre la dinámica cultural de los pueblos ${ }^{6}$. De particular interés resulta indagar la forma en que la fuerza de trabajo, al igual que años atrás las mercancías, se traslada de las periferias al centro, como una mercancía más. Movimiento que obliga a pensar en las relaciones y prácticas sociales, en la comunidad de origen y en el lugar de la recepción. En este sentido, uno de los más importantes aportes ha sido el concepto de espacio social transnacional, acuñado por primera vez por Roger Rouse en 1991 y que daría pie para reconocer las múltiples combinaciones de relaciones y prácticas sociales surgidas a raíz de la migración internacional. Para este autor, a través de la migración, los sujetos, sus prácticas sociales, culturales y políticas pueden transformarse y ellos mismos pueden intervenir para trocar la organización prevaleciente en sus lugares de origen (Rivermar Pérez 2005:1).

A partir de estos planteamientos, la migración es vista como un proceso que va forjando nuevos espacios, una multiplicidad de relaciones y la expansión de las fronteras. Términos como transnacionalismo, los transmigrantes, la transnacionalización, desterritorialización, nuevas apropiaciones del espacio y espacios sociales transnacionales son conceptos ofrecidos por diversos investigadores para intentar dar cuenta de las nuevas realidades migratorias ${ }^{7}$.

Tal es el caso de Michael Kearney, para quien la noción de transnacionalismo le permite comprender a un nuevo tipo de inmigrantes con vínculos socioculturales fuertes, tanto en el país de origen como en el receptor, y considera por esto, que a los pertenecientes a estas comunidades es pertinente caracterizarlos como transmigrantes (Kearney 1996).

Siguiendo con la idea de conexión, Ulf Hannerz destaca que la gente que conforma estos flujos migratorios mantiene vínculos con sus lugares de origen y que sin la presencia de estas personas en las ciudades centro éstas perderían su carácter global (Hannerz 1993:67-81).

Por mi parte, si bien reconozco la existencia de estos vínculos y la complejidad de las relaciones que, pese a la distancia, persisten entre la comunidad de origen y la comunidad destino, no dejo de preguntarme ¿cómo enfrentan la migración los que se van y los que se quedan? Y en este sentido, en este trabajo me interesa resaltar la manera que los teenek y nahuas de la Huaxteca, los que permanecen en sus lugares de origen y los que se desplazan hacen frente a tal fenómeno. 
Y lo haré intentando tomar como referente el concepto de formas simbólicas utilizado por John B. Thompson, con la intención de destacar los usos sociales que las poblaciones afectadas por la emigración hacen de éstas; para ello, intentaré identificar los diversos modos en que opera la ideología y algunas de las estrategias típicas de la construcción simbólica.

Cuando John B. Thompson manifiesta su inclinación por los usos sociales de las formas simbólicas, declara que su interés se da en el sentido de

saber en qué medida y de qué manera sirven (si es que lo hacen) las formas simbólicas para establecer y sostener las relaciones de dominación en contextos sociales dentro de los cuales se producen, transmiten y reciben (Thompson 1993:9).

No obstante lo anterior, continúa señalando,

este enfoque puede llevarnos a considerar una forma o un sistema simbólico como ideológico en un contexto y como radical, subversivo o contestatario, en otro; por ejemplo, puede llevarnos a considerar un discurso acerca de los derechos humanos como sustentador del statuo quo en un contexto y como subversivo en otro. El análisis de las formas simbólicas en tanto ideológicas requiere que las analicemos en relación con los contextos sociohistóricos específicos dentro de los cuales se emplean y sostienen (Thompson 1993:9).

Si los sistemas ideológicos cobran diversos sentidos, dependiendo del contexto sociohistórico en el que se inscriban, entonces cabe preguntarnos de qué manera y en qué medida sirven las formas simbólicas para cohesionar a las poblaciones indígenas ante los desajustes sociales y económicos que padecen por la salida de una importante fuerza de trabajo.

$\mathrm{Y}$ es en este sentido que me propuse analizar el uso de las formas simbólicas. Dejo de lado la connotación que une lo ideológico con la idea de falsedad ${ }^{8}$, haciendo énfasis en la relación que guarda con la noción de poder y la de dominación, para quedarme con la forma en que Teun A. van Dijk intenta desarrollar una nueva noción de ideología que sirva de interfase entre la estructura social y la cognición social (van Dijk 2000). Coincido con el autor al considerar:

hay ideologías de oposición y resistencia, o ideologías de competencia entre grupos igualmente poderosos, o ideologías que sólo promueven la cohesión interna del grupo, o ideologías sobre la supervivencia de la humanidad. Esto implica que, en mi enfoque, las ideologías no son inherentemente negativas ni se limitan a estructuras sociales de dominación (van Dijk 2000:25).

Me parece pertinente dejar de lado las antiguas concepciones que dieron a la ideología el sentido de falsa conciencia, para considerar la existencia de ideologías que se pueden definir como la base de las representaciones sociales compartidas por los miembros de un grupo.

Ideologías que permiten a las personas, como miembros de un grupo, organizar la multitud de creencias sociales acerca de lo que sucede, ya sea bueno o malo, correcto o incorrecto, según su propia visión del mundo, y actuar en consecuencia (van Dijk 2000:21), a través de formas simbólicas que en términos culturales se producen, construyen y emplean para determinado objetivo o propósito.

En este sentido, me interesa abordar culturalmente el fenómeno de la migración en la Huaxteca a través de los siguientes objetivos:

(1) Describir el contexto social en el que se inscribe el proceso de emigración.

(2) Dar cuenta de la diversidad de aspectos socioculturales que se relacionan con el fenómeno de la migración.

(3) Dar cuenta de la forma en que la población indígena, a través de diversas formas simbólicas, enfrenta la emigración.

\section{El Contexto Social}

La Huaxteca abarca porciones de cinco estados de México: San Luis Potosí, Tamaulipas, Veracruz, Hidalgo, Puebla y Querétaro; estados que confluyen delimitados por los ríos Cazones y Soto la Marina, para integrar un extenso espacio en el que aflora la diversidad de zonas climatológicas, geográficas y culturales. En efecto, la Huaxteca conforma un verdadero mosaico natural y cultu- 
ral en el que habitan teenek, nahuas, otomies, tepehuas y pames (Figura 1); grupos étnicos que se dispersan entre la costa y las llanuras costeras del Golfo y la Sierra Madre Oriental, el Altiplano Potosino y la abrupta Sierra de Tamaulipas (Puig 1976:15-30); recreando sus respectivas creencias, costumbre, experiencias, conocimientos, pensamientos, normas y valores.

Grupos indígenas que basan su alimentación en el maíz (Zea mays) y el frijol (Phaseolus vulgaris), complementando su dieta con chile (Capsicum), calabaza (Cucurbita) y hortalizas; que cultivan, café (Coffea arabica), naranja (Citrus aurantium) y si acaso se dedican algunos a la ganadería en pequeña escala. Los indígenas campesinos que combinan sus ingresos con la agricul- tura y el trabajo asalariado logran comprar entre dos y cinco cabezas de ganado indobrasil ${ }^{9}$ que les permite contar con un capital para casos de emergencia.

Destacan por su presencia histórica los teenek que viven en San Luis Potosí y en Veracruz; de la misma manera y por su importancia numérica, los nahuas en la porción sur de la Huaxteca, en los estados de Puebla, Veracruz, Hidalgo y San Luis Potosí.

No obstante la existencia de tal riqueza natural y cultural, en las tierras donde se asientan estos grupos étnicos se presenta la otra cara de la opulencia, la de la pobreza. Y se asoma como resultado de un histórico proceso en el cual los grupos oligárquicos, las burguesías de todos los tiempos descubrieron la riqueza de dichos lugares. El re-

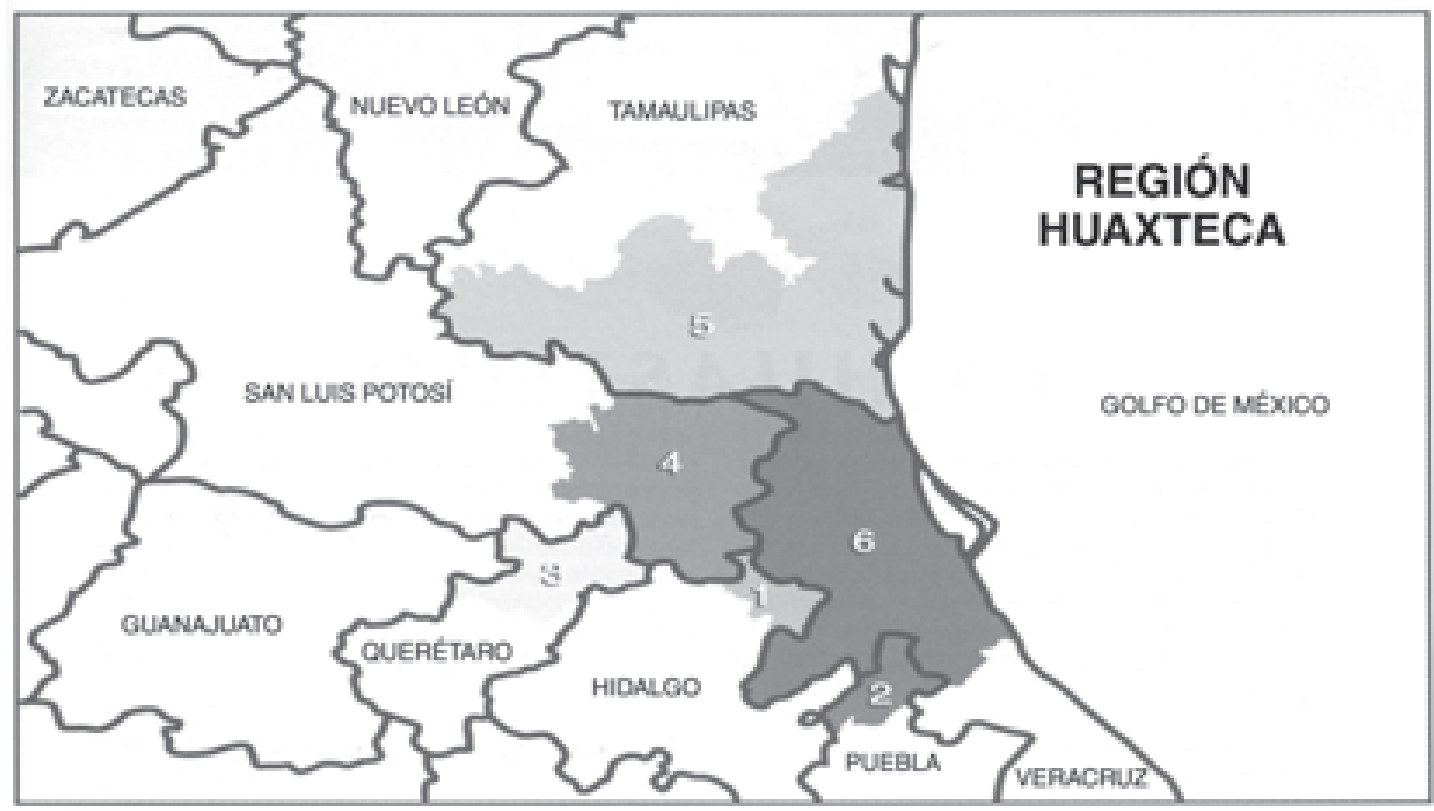
HUAXTECA DE HIDALGO
HUAXTECA DE PUEBLA
HUAXTECA DE QUERÉTARO
HUAXTECA DE SAN LUIS POTOSÍ
HUAXTECA DE TAMAULIPAS
6 HUAXTECA DE VERACRUZ

ESCALA 1:4,125,674

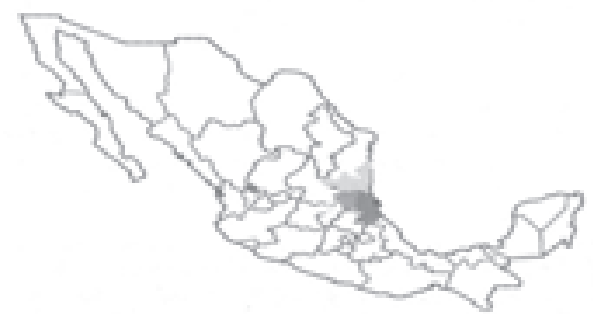

FUENTES: Delimitación Administrativa de la Región Huaxteca de la DGVC CONACULTA; ITER 2000, INEGI. ELABORADO: Departamento de Proyectos y Contenidos Electrónicos de la DGCPI-CONACULTA 22/04/04. 
sultado, al igual que en otras partes, fue el despojo, la usurpación y la concentración de tierras y recursos. Aunado al despojo territorial, el auge petrolero que se inicia a principios del siglo $\mathrm{XX}$ sólo trajo miseria y terrenos contaminados.

Pero si bien la raíz de la pobreza es resultado de las relaciones sociales propias del sistema capitalista, no puede dejarse de lado que también la naturaleza contribuye para acentuar la diferenciación social; la región sufre de heladas, sequías e inundaciones que aniquilan las cosechas y crean un precario equilibrio de sobrevivencia. Por ello, pese a la riqueza de los recursos de la Huaxteca, los grupos étnicos que la habitan pertenecen al sector de la población más pobre del país ${ }^{10}$.

No es de extrañar pues, que al igual que en otros lugares de México, y como resultado de más de tres sexenios de políticas erráticas dirigidas a la actividad agrícola, los huaxtecos empezaran a emigrar; influyendo sin duda, los conflictos agrarios que ocasionaron infinidad de muertes de indígenas a manos de terratenientes y ganaderos de las huaxtecas Potosina, Hidalguense y Veracruzana. De tal forma si bien puedo considerar que principalmente emigran indígenas campesinos empobrecidos y jornaleros sin tierra, tampoco puedo dejar de lado a otros sectores que por diversas causas también desean buscar otro modo de vida, como es el caso de pequeños productores y ejidatarios con buena posición económica, hijos de maestros o técnicos, familiares de caciques, los que buscan dejar atrás su condición de indios, o los que buscan mejorar sus condiciones económicas. La migración y el trabajo puede ser parte de las estrategias para consolidar su situación de productores.

\section{Primer Movimiento: la Salida}

La emigración empezó a cobrar importancia en las tierras huaxtecas cuando hace quince años, en San Luis Potosí e Hidalgo se impulsan las contrataciones para el corte de tomate (Lycopersicon esculentum Mill.) y chile. Cuenta don Juan ${ }^{11}$ que se promocionaban por medio de las radiofusoras locales y se mandaban camiones por la gente para ir a trabajar a los campos agrícolas de Sinaloa ${ }^{12}$.

Pero lo que al principio fue para los indígenas campesinos una salida temporal de dos o tres meses, acorde con la duración del proceso productivo del tomate y del chile, fue dando paso a la decisión de emigrar en forma permanente hacia las ciuda- des de Poza Rica, Tampico, San Luis Potosí, Pachuca y México; ciudades en las que se arroparon en la economía informal y en los servicios.

Las causas del fuerte movimiento migratorio, si bien en lo personal pueden tener explicaciones diversas, a nivel social sin duda son resultado de políticas sexenales encaminadas a transformar el país. En efecto, modernizar al país fue el objetivo seguido en los años de 1990 y para ello, por demás ilustrativo resulta recordar lo dicho por el entonces Secretario de Agricultura, el Prof. Hank González: "Mi obligación como secretario de Agricultura es sacar del campo a diez a millones de campesinos", declaró el profesor Hank en una rueda de prensa en 1991. "Y que hará con ellos?", le preguntó un periodista. "Esa no es mi área de trabajo", respondió Hank. Ocuparse realmente de ellos no era trabajo suyo ni de nadie" (Esteva 2003:205) ${ }^{13}$.

Con las reformas al artículo 27 Constitucional ${ }^{14}$ y la cancelación del reparto agrario, como parte de la política de Carlos Salinas de Gortari ${ }^{15}$, se logró el objetivo del profesor: "liberar" a los campesinos.

Otro aspecto que influyó también en el movimiento migratorio fue el declive petrolero, que a finales de la década de los años ochenta fue eliminando la contratación de trabajadores transitorios en los estados de Veracruz y Tamaulipas.

Ante este panorama, los jóvenes empezaron a dirigir sus pasos a las poblaciones fronterizas donde se instalaron las maquiladoras. Este éxodo pronto se vio reflejado en los datos censales y para 1995, de acuerdo a la información de indicadores socioeconómicos de los pueblos indígenas en México (Serrano et al. 2002), el 1\%, en promedio, de la población de los municipios de las Huaxtecas Veracruzana, Potosina e Hidalguense, vivía en otro lugar, como se aprecia en la Tabla 1.

Lo que se iniciaba a fines del siglo pasado, cobra intensidad. En este sentido, para 2003, la salida de los jóvenes y adultos se intensifica de tal forma que las empresas camioneras Coordinados ABC y el ADO aprovechan la demanda y abren nuevas rutas a los lugares donde hay fuentes de trabajo, incrementando en poco tiempo el número de salidas a Reynosa, Matamoros, Ciudad Acuña y Juárez, entre otros puntos (Tablas 2 y 3). Destinos en los que no sólo abundaba la oferta laboral, sino que también se convertían en puntos estratégicos desde los cuales era posible internarse a la Unión Americana ${ }^{16}$. 
Tabla 1. Emigración Huaxteca en 1995.

Huaxteca emigration in 1995.

\begin{tabular}{|c|c|c|c|c|c|c|}
\hline Estado & Población & $\begin{array}{l}\text { Total de } \\
\text { población }\end{array}$ & $\begin{array}{l}\text { Lugar } \\
\text { residencia }\end{array}$ & $\%$ & En otra entidad & $\%$ \\
\hline \multirow{8}{*}{ Hidalgo } & Atlapexco & 14.860 & 14.578 & 98,1 & 251 & 1,7 \\
\hline & Huautla & 19.895 & 19.550 & 98,3 & 315 & 1,6 \\
\hline & Huejutla & 77.287 & 75.863 & 98,2 & 1.206 & 1,6 \\
\hline & Huazalingo & 8.670 & 8.599 & 99,2 & 56 & 0,6 \\
\hline & Jaltocan & 8.831 & 8.723 & 98,8 & 90 & 1,0 \\
\hline & San Felipe Orizatlán & 25.455 & 25.026 & 98,3 & 389 & 1,5 \\
\hline & Xochiatipan & 14.443 & 14.237 & 98,3 & 76 & 0,5 \\
\hline & Yahualica & 17.243 & 16.956 & 98,3 & 228 & 1,3 \\
\hline \multirow{9}{*}{ San Luis de Potosí } & Aquismón & 27.874 & 27.665 & 99,3 & 106 & 0,4 \\
\hline & Tancanhuitz de Santos & 14.372 & 14.238 & 99,1 & 106 & 0,7 \\
\hline & Ciudad Valles & 18.541 & 18.118 & 97,7 & 379 & 2,0 \\
\hline & Tamazunchale & 51.058 & 50.288 & 98,5 & 709 & 1,4 \\
\hline & Tampacan & 9.791 & 9.691 & 99,0 & 87 & 0,9 \\
\hline & Tampamolon & 9.887 & 9.790 & 98,3 & 72 & 0,7 \\
\hline & Tamuin & 6.274 & 6.197 & 98,3 & 99 & 1,6 \\
\hline & Tanlajas & 14.401 & 14.430 & 99,4 & 56 & 0,4 \\
\hline & Xilitla & 24.218 & 23.818 & 98,3 & 341 & 1,4 \\
\hline \multirow{10}{*}{ Veracruz } & Benito Juárez & 6.847 & 6.828 & 99,7 & 17 & 0,1 \\
\hline & Citlaltépetl & 4.709 & 4.592 & 97,5 & 109 & 2,3 \\
\hline & Chicontepec & 47.874 & 47.145 & 98,5 & 399 & 8 \\
\hline & Las Choapas & 5.991 & 5.679 & 94,8 & 297 & 5,0 \\
\hline & Chontla & 7.398 & 7.324 & 99,0 & 65 & 0,9 \\
\hline & Ilamatlán & 10.488 & 10.225 & 97,8 & 117 & 1,1 \\
\hline & Tancoco & 6.254 & 6.110 & 98,8 & 140 & 1,2 \\
\hline & Tantoyuca & 56.258 & 55.623 & 98,9 & 495 & 0,9 \\
\hline & Tepetzintla & 5.363 & 5.281 & 98,5 & 73 & 1,4 \\
\hline & Tuxpan & 6.038 & 5.830 & 96,6 & 195 & 3,2 \\
\hline
\end{tabular}

Tabla 2. Migración de mayores de cinco años (2000).

Migration of persons older than five years of age (2000).

\begin{tabular}{|c|c|c|c|c|c|c|}
\hline Estado & Lugar & $\begin{array}{l}\text { Población } \\
\text { total }\end{array}$ & $\begin{array}{l}\text { Total de } \\
\text { emigrantes }\end{array}$ & $\begin{array}{l}\text { Migración a } \\
\text { otra entidad }\end{array}$ & $\begin{array}{c}\text { Migración a } \\
\text { otro país }\end{array}$ & $\begin{array}{c}\text { No } \\
\text { especificado }\end{array}$ \\
\hline \multirow{2}{*}{ Hidalgo } & Huazalingo & 9.624 & 72 & 70 & 2 & 24 \\
\hline & Huejutla & 94.498 & 2.562 & 2.538 & 24 & 353 \\
\hline \multirow{2}{*}{ San Luis Potosí } & Coxcatlán & 15.222 & 243 & 239 & 4 & 53 \\
\hline & Tanquián de Escobedo & 11.842 & 280 & 267 & 13 & 31 \\
\hline \multirow{5}{*}{ Veracruz } & Benito Juárez & 14.004 & 141 & 141 & 0 & 37 \\
\hline & Ixhuatlán de Madero & 43.101 & 783 & 781 & 2 & 123 \\
\hline & Tancoco & 5.591 & 154 & 153 & 1 & 13 \\
\hline & Tantoyuca & 82.422 & 1.211 & 1.207 & 4 & 423 \\
\hline & Tepetzintla & 12.051 & 243 & 243 & 0 & 32 \\
\hline
\end{tabular}

Fuente: XII Censo General de Población y Vivienda, 2000. Resultados Definitivos. Tabuladores Básicos. Aguascalientes, México.

En este sentido, con población de Tamaulipas, San Luis Potosí, Querétaro, Veracruz e Hidalgo, para fines de ese año, se conformó el 5,9\% del total de emigrantes que han pasado "al otro lado"17.
Buscaban dejar atrás la imposibilidad de obtener tierras, las limitadas condiciones laborales y los menguados salarios mínimos de 4 dólares que obtienen al día, para soñar con ganar en los Estados 
Tabla 3. Dos destinos importantes de la emigración (2000). Two important destinies for migration (2000).

\begin{tabular}{llrr}
\hline \multirow{2}{*}{ Estado } & Lugar de origen & $\begin{array}{l}\text { Distrito } \\
\text { Federal }\end{array}$ & Tamaulipas \\
& Huazalingo & 28 & 11 \\
Hidalgo & Huejutla & 840 & 530 \\
& Coxcatlán & 104 & 50 \\
San Luis Potosí & Tanquián de Escobedo & 62 & 151 \\
& Benito Juárez & 45 & 10 \\
& Ixhuatlán de Madero & 281 & 34 \\
Veracruz & Tancoco & 55 & 91 \\
& Tantoyuca & 435 & 896 \\
& Tepetzintla & 79 & 45 \\
\hline
\end{tabular}

Fuente: XII Censo General de Población y Vivienda, 2000. Resultados Definitivos. Tabuladores Básicos. Aguascalientes, México.

Unidos hasta 9,50 de dólar por hora. Factores que también en otras partes, en otros estados, han provocado la emigración ${ }^{18}$.

De esta manera, la cultura huaxteca se ha puesto en movimiento; un movimiento que poco a poco va llevando a los huaxtecos a traspasar sus fronteras culturales y territoriales para intentar llegar hasta Carolina del Norte, en el territorio norteamericano. Cruzar la frontera, sin embargo, no ha sido ni es tarea fácil. La línea trazada arbitrariamente ha sido el límite establecido para delinear e inscribir diferencias. Donde se delimita la línea empieza el "otro" y no faltan las estructuras concretas e imaginarias que marcan una distancia, al menos simbólica, respecto a ese "otro". Tal vez un ejemplo concreto se establece cuando consideramos la visión popular de la migración. Trabajadores migratorios se reconocen todos los que van a Estados Unidos a buscar trabajo, illegal aliens (forasteros ilegales) les llama la población estadounidense que no pone en duda que los grandes males del país son ocasionados por éstos ${ }^{19}$.

No obstante, las mil y una experiencias negativas que los emigrantes pueden contar en su intento por trabajar en los Estados Unidos, de las múltiples violaciones a sus derechos y de la discriminación racial ${ }^{20}$, día con día son más los huaxtecos que amenazan cruzar la cerca metálica o los cauces de los ríos, en busca de trabajo. Las razones, como hemos visto, varían, pero vale la pena destacar el caso de los pescadores. En este sentido, un Diario de Tuxpan, Veracruz, en el año de 2003 destacó entre sus noticias que aproximadamente 100 pescadores de la Laguna de Tampa- machoco, en Veracruz ${ }^{21}$, amenazaron con irse a los Estados Unidos en busca de trabajo. Las causas aludidas hicieron referencia a las condiciones climáticas que se avecinaban para los meses que restaban del año, mismas que no les permitirían capturar las especies de mayor demanda en el mercado. De esta forma, el periódico registró:

El centenar de trabajadores manifestó su deseo de trabajar en EU porque el trabajo en ese país es bien remunerado, y consideran que puede ser su nueva forma de ganar dinero para mantener a sus familias aunque deban abandonarlas por tiempo indefinido (Leyva 2003).

\section{Las Marcas de la Emigración}

La emigración actual en las Huaxtecas es una realidad inevitable; un proceso en el que participan hombres jóvenes, mujeres y hasta familias enteras. Inútil ignorarla cuando por todos sus pueblos encontramos una serie de marcas que aluden a la migración, como son las empresas por las que se envía dinero, las líneas de autobuses ofreciendo sus servicios a lugares fronterizos, los canales de comunicación que Radio MAS, en Jalapa, en el estado de Veracruz, logró establecer para permitir la comunicación entre locales e inmigrantes, los listones de color blanco que se ofrecen a San Chárbel Majluf ${ }^{22}$, los milagros y veladoras que frente a la virgen de Guadalupe se depositan para pedir por la protección para el familiar ausente.

Por su parte, en los pueblos y rancherías el fenómeno migratorio se hace tangible tan sólo al contemplar la vivienda. En efecto, si bien es posible todavía observar en el paisaje de la Huaxteca la presencia de las casas tradicionales construidas con paredes de embarro ${ }^{23}$ y techos de palma, también es posible observar que algunas están deshabitadas dado el inminente descuido en el que han caído. En otras casas es por demás notoria la gran inyección de recursos destinados a transformarlas. Las nuevas construcciones se hacen de ladrillo y cemento, de dos pisos y con todos los servicios, acordes a lo que es el concepto moderno de residencia.

De la misma manera, es posible observar que la reproducción social de muchas comunidades indígenas ya no depende de los recursos de la agricultura; las remesas que envían los que han emigrado se invierten en el comercio y en la compra 
de ganado provocando lo que bien podríamos llamar una nueva reconfiguración social provocada por la migración.

Los constantes desplazamientos de los habitantes de las comunidades de origen a los lugares en los que habitan los que emigran, permite un contacto intenso y acelerado con los universos extracomunitarios provocando la adopción de modas urbanas, cambios en el hábitat, en la forma de hablar y de alimentarse.

\section{El Equipaje Cultural: lo que se Guarda y lo que se Usa}

Pero si en las poblaciones de origen se observa los cambios en el vestir, en los lugares de recepción, como son Ciudad Juárez, Piedras Negras, Reynosa y Matamoros ${ }^{24}$, del lado mexicano, y Carolina del Norte en los Estados Unidos (Figura 2), acuden indígenas de diversas filiaciones étnicas que no sólo abandonan definitivamente el traje tradicional, sino que incluso tienden a cambiar de nombre bajo el argumento de que "suena muy indio, se burlan de uno" (Valle 2003:294). Expresiones que dejan ver la brutal discriminación ra- cial de la que son víctimas en los lugares de trabajo, tanto en México, como en los Estados Unidos.

En los lugares de recepción cada vez es más frecuente oír de la unión matrimonial entre $n a$ huas de la Huaxteca con totonacas de Papantla, Veracruz por citar sólo un ejemplo. Estas uniones dan cuenta de la pérdida de las antiguas alianzas que se llevaban a cabo sólo entre integrantes de un mismo grupo a través del matrimonio. Alianzas que se establecían entre familias que acordaban la unión de sus hijos y que propiciaban intercambios en trabajo y en productos; reciprocidad y ayuda mutua sobre todo en el proceso productivo. Las uniones fuera del ámbito comunal nos permiten también visualizar la desaparición de las aún posibles tendencias endogámicas ${ }^{25} \mathrm{e}$ incluso exogámicas ${ }^{26}$ existentes entre los grupos étnicos ${ }^{27}$ de la región estudiada, para dar paso al matrimonio homogámico o isogámico, a la unión de parejas que ostentan la misma condición social ${ }^{28}$.

En este sentido, hombres y mujeres de diversas procedencias se encuentran en las maquiladoras, en los lugares donde prestan sus servicios y los barrios obreros; se unen así nada más, sin ningu-

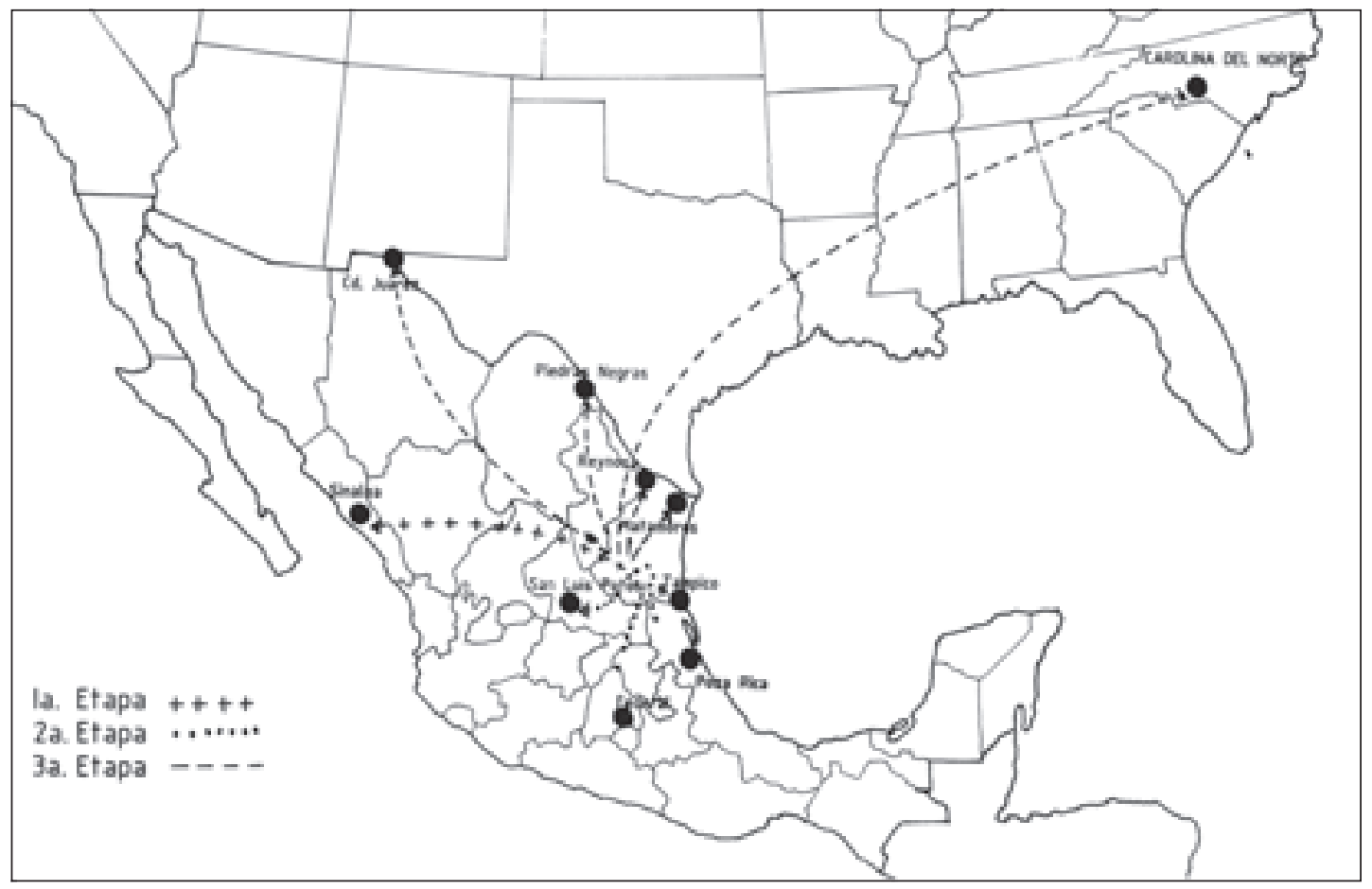

Figura 2. Las rutas de la emigración.

The immigration routes. 
na ceremonia ritual ${ }^{29}$ que preceda al matrimonio, como todavía se acostumbra entre algunos grupos nahuas y teene $k^{30}$. Se unen culturas distintas que, sin duda, pueden hacer surgir otros parámetros socioculturales que darán origen a nuevas formas de reglamentar y considerar la parentela.

El lugar de residencia de la pareja tampoco puede seguir las pautas de patrilinialidad y patrilocalidad que regían la tradición, ya que ésta no puede instalarse en el solar de la familia del hombre ni mucho menos esperar que se les asigne un terreno. La vivienda en la frontera o en los Estados Unidos depende de sus propios recursos y de la disponibilidad de la misma.

No obstante los cambios en lo que se refiere a las reglas del matrimonio y residencia, es importante destacar que en los lugares destino, una vez que los emigrantes logran una estabilidad laboral, la memoria del "hogar-lugar," como señalan Gupta y Ferguson (1992) es clave para la construcción del nuevo hogar y para la unificación y movilización de los grupos móviles o desplazados. Así, en la Esperanza, en el norte de Veracruz es frecuente escuchar que familias enteras se han ido a vivir a Matamoros, Tamaulipas (Tabla 3), reproduciendo, aunque tal vez con otros parámetros, lo que se antoja ser la trilogía de la organización social: la filiación, la alianza y la residencia.

No obstante lo anterior, es importante señalar que los emigrantes reúnen dinero y envían por sus padres; éstos abandonan su casa y su milpa para vivir con los hijos y depender de los mismos. Con este cambio resulta por demás anotar que los padres han perdido el dominio económico e ideológico que anteriormente tenían sobre sus hijos en la medida que a éstos ya no les interesa recibir como herencia un pedazo de tierra.

Los efectos del desplazamiento son múltiples y contradictorios. Si bien he intentado resaltar los cambios que se están dando en los grupos étnicos, no es menos importante aludir a lo que pareciera ser su imperiosa necesidad de perdurar. En este sentido, me interesa destacar ahora las formas en que los inmigrados explayan sus prácticas, creencias y tradiciones culturales.

En los lugares destino pareciéramos encontrar lo que se antoja ser una extensión del territorio de origen, una expansión territorial; se lleva lo propio, algunas prácticas y creencias privativas de su cultura indígena campesina tradicional ${ }^{31}$. Mantienen la traición oral y recurren a los me- dios modernos de comunicación; de forma tal que a través de la radio ${ }^{32}$, el teléfono y de los cafés Internet que desde principios del siglo se expanden por todos los poblados, logran estar al tanto unos de otros, de lo que sucede y de los eventos importartes de los dos universos de vida: la comunidad y la sociedad receptora.

El viaje se vuelve una forma de vida. Los emigrantes, los que pueden hacerlo ${ }^{33}$, regresan a sus comunidades para las celebraciones de muertos, del Santo Patrono o para la Navidad. De tal forma, en estas fechas es posible contemplar por las carreteras del Golfo, verdaderas caravanas de autos llenos de gente y obsequios. Filas de personas $\mathrm{y}$ objetos que en procesiones modernas se desplazan a sus lugares de origen para realizar lo que se antoja un "ritual de reconstitución comunitaria" 34 .

Por su parte, los que se quedan, como son los familiares, aprovechan las vacaciones para irlos a visitar llevando consigo los sabores de sus cocinas. De la misma forma, los vendedores de zacahuil, de carne enchilada, queso y camarón y los revendedores de pan también se desplazan a los lugares hoy habitados por los emigrantes logrando introducir sus productos en los mercados locales de la Ciudad de México, Reynosa, Matamoros y aun de los Estados Unidos.

Las creencias y prácticas mágicas, uno de los aspectos más prominentes de la cultura tradicional, se desplazan también a los nuevos espacios de vida. Así, los curanderos son solicitados y acuden a las peticiones de sus paisanos para curar sus enfermedades. Su eficacia en el arte de curar trasciende en este sentido el ámbito local y regional, logrando incluso que sus conocimientos y maestría para atender las enfermedades sean conocidos y demandados por otros inmigrantes de orígenes diversos.

En este sentido, es posible considerar, como señala Anath Ariel de Vidas, que con la migración se “... transforma la concepción de los territorios comunales que se extiende actualmente por la multipolaridad de los espacios de vida" (comunicación personal, 2005).

\section{Activando el Mundo Simbólico Para Enfrentar la Emigración}

Si miramos el lugar de origen, podemos ver otra faceta de la migración. La salida de los emi- 
grantes de sus lugares de origen implica procesos complejos de confrontación, negociación y adaptación; se sabe de las ventajas de emigrar, pero no por ello se evitan los conflictos y las tribulaciones de las comunidades. Dicen que debe perdurar la autoadscripción del que se va respecto a la comunidad que se queda, y el reconocimiento colectivo de los que se quedan respecto a la pertenencia comunitaria de los que se van (PérezRuiz 2002:314), pero para lograrlo la comunidad debe poner en movimiento su cultura, ese conjunto de acciones y lenguajes, imágenes y textos que tienen un significado para el grupo social, que se transmiten y circulan en sus respectivos contextos sociales ${ }^{35}$, erigiéndose en verdaderas guías para la acción del grupo social. Conjunto que constituye formas simbólicas insertas en relaciones sociales estructuradas.

\section{(a) La emigración frente a la legitimidad política}

En el plano organizativo, el conjunto complejo de signos, símbolos, normas, modelos, actitudes, valores y mentalidades (Geertz 1992, Thompson 1993) se ponen en circulación para evitar que las comunidades huaxtecas sucumban ante la salida de sus integrantes.

Tal es el caso de Benito Juárez, población náhuatl del estado de Veracruz. Aquí, si bien en 1995 sólo aparecían 17 individuos viviendo en otra población, para 2003 el número de emigrantes había aumentado a más del doble (Tablas 2 y 3$)^{36}$. Para hacer frente a este movimiento en ascenso, la población que se rige por la organización comunal determinó quiénes y por cuánto tiempo debían salir a trabajar fuera. Organización necesaria ante la cada vez más frecuente insistencia de los jóvenes entre 20 y 35 años por salir a buscar en los Estados Unidos mejores ingresos. Por ello, y como todos son ejidatarios, el Comisariado Ejidal y la asamblea determinaron que los que se fueran debían tener un permiso de 1 a 2 años y después de este plazo regresar para que otros pudieran a su vez también salir por un tiempo similar. Migración por relevos ${ }^{37}$ podríamos considerar a este tipo de arreglos que logran asegurar que siempre haya campesinos para trabajar la tierra ${ }^{38}$.

En Hueycoatitla, poblado cercano a Benito Juárez, el régimen de propiedad de la tierra es comunal. Aquí, los agentes municipales hicieron un reglamento interno en el que además se especifica que se debe cumplir con la tradición de realizar faenas ${ }^{39}$ cada 15 días. El arreglo para los ausentes se estableció por asamblea, acordando que el que no esté debe mandar de 2 a 5 dólares por faena, cuando le toca.

Así, sobre esta base, la expresión de las formas simbólicas se da por medio de una estrategia de racionalización, por la cual las autoridades comunales de Benito Juárez y de Hueycoatitla construyen una serie de razonamientos que permitan asegurar la reproducción social de la comunidad. Así, mientras que en el primer caso se ponen candados a la migración para evitar la salida masiva de los jóvenes en edad reproductiva, en la medida que la prolongación de su ausencia limita las posibilidades de uniones matrimoniales, y también porque esta joven mano de obra abandonaría el trabajo de la milpa provocando el enojo de D'hipaak, la deidad del maíz ${ }^{40}$. En el segundo caso se busca perpetuar un sistema de antaño practicado, como son las faenas, aludiendo a lo que se antoja ser una estrategia de la universalización. Y estimo que responde a tal carácter, por considerar que la legitimidad de las medidas tomadas en uno y otro caso parte de bases tradicionales que apelan a la inviolabilidad de las tradiciones inmemoriales ${ }^{41}$; es la obligación primordial que tienen los integrantes de la comunidad de participar en una serie de trabajos, como las faenas, las cuotas, la participación en los cargos y las decisiones colectivas, para la preservación de todo el orden comunal ${ }^{42}$.

En uno y otro caso, cuando los emigrantes no cumplen con los acuerdos establecidos por la asamblea, la ideología comunal opera recurriendo a la fragmentación; estratégicamente se busca la expurgación de los que contravienen las disposiciones en la medida que ponen en peligro la reproducción social de sus poblaciones ${ }^{43}$. De tal manera y como modo de operación ideológico opuesto a la fragmentación, se busca unificar a las poblaciones a través de la simbolización de unidad y al papel tan importante que en ella juega su tradicional sistema político.

\section{(b) Castigo y curación: activando el mundo simbólico para enfrentar la emigración}

Los habitantes de la Huaxteca van dejando de sembrar maíz; unas veces porque no tienen 
más tierras para hacer sus siembras (milpas), otras, como es el caso de algunos campesinos de Benito Juárez, de Colatlán en el estado de Veracruz, de Tzapujá, de Tanquián, y de Coxcatlán en de San Luis Potosí, porque señalan que el "clima ya no es igual," falta o hay exceso de lluvia, y por los fuertes vientos que dañan y tumban las milpas. Dicen ${ }^{44}$ que "todos son pobres porque siembran maíz y luego no llueve y no tienen para comer ni nada más", “... porque no tienen estudios, ni conocimientos para hacer que la tierra produzca más". En otros casos, aseguran que la tierra está cansada y “... ya nada más sale la cosecha muy chiquita". En San Nicolasi1lo, en el estado de Hidalgo, dicen que el maíz no se da porque hay muchos animales que no lo dejan crecer como los tejones y los mapaches. Con nostalgia, en Santa María Ixcatepec, Veracruz, recuerdan, "cuando los abuelos vivían había maíz, ahora ya no se da".

Pero además de los fenómenos naturales, encontramos otras razones, que sin ser conocidas a ciencia cierta por los pobladores del Huaxteca, son las que han propiciado la crisis agrícola en México ${ }^{45}$ y el abandono de la agricultura. El proyecto modernizador impulsado en el sexenio de Carlos Salinas logró la "liberación" de miles de campesinos. De las comunidades y ejidos, de pueblos y rancherías fueron saliendo a buscar trabajo en las maquiladoras del norte del país. Lugares en los que además buscaban la forma de cruzar la frontera.

La salida masiva provocó que el campo se empezara a despoblar. La mano de obra que se quedaba, resultaba insuficiente para seguir trabajando las milpas. Y dejar de sembrar maíz es un gran peligro para la sobrevivencia de los grupos indígenas campesinos. Acaso, sea la razón por la cual, en Tancoco, Veracruz, recurren a diversas creencias del mundo simbólico para enfrentar el abandono de la agricultura; recurren a lo que bien podríamos nombrar culturalmente una estrategia vengativa ${ }^{46}$ : el enojo de santos y deidades. Así, los teenek consideran que: ... si uno deja de sembrar o de cosechar su milpa, si abandona su labor, entonces el $D^{\prime}$ hipaak ${ }^{47}$ se venga, se enoja y causa enfermedad muy grave en la persona, tan grave que puede llegar a morir, porque el D'hipaak es el más pesado de todos, no es una persona, son muchas" (don Polo, comunicación personal, 2004).
Los "alcanza el maíz" se dice y el cuerpo del alcanzado empieza a ponerse blandito hasta que, si no son atendidos, llegan a morir. La atención para el enfermo, sin embargo, no puede ser tarea de cualquier médico, sólo los especialistas de las mismas comunidades, los que participan de sus mismas creencias y tradiciones pueden curar, y lo hacen barriendo el cuerpo del alcanzado con una mazorca, le preparan su zacahuil ${ }^{48}$ y le rezan a D'hipaak. De esta manera, la población construye simbólicamente estrategias de dependencia y efectividad relacionadas con su visión del mundo; estrategias que obligan ideológica y culturalmente a quienes abandonan su comunidad y su milpa, a regresar a curarse, reincorporarse a la comunidad y seguir cultivando.

\section{(c) Rituales y ofrendas: activando el mundo simbólico para enfrentar la emigración}

Desde el siglo XVI se conoce el concepto de alma introducido por los evangelizadores. Hoy día, los huaxtecos piensan que cada persona tiene un alma, ehatal, y un espíritu; ehatal y ts'itsiin son complementarios. El ehatal proporciona el don del habla, mientras que el $t s^{\prime}$ itsiin representa la voluntad y reside en la cabeza; a través de éste los árboles, las personas o cualquiera puede adueñarse de la voluntad de los otros. Un tercer centro en el cuerpo humano sería el corazón, que refleja la fuerza y las emociones del individuo (Alcorn 1984:67-68).

Cuando el esposo o los hijos dejan su población para buscar trabajo en cualquier ciudad de México o en los Estados Unidos, se provoca una profunda tristeza. Los alcanza la tristeza se dice en la Huaxteca, y ésta parecería quedar instalada en el corazón tanto de los que se quedan, como en el de los que se van; la padece el corazón, el yol, yollo, yóllotl para los nahuas (López Austin 1980:152-200), el ichich para los tennek (Tapia de Zenteno 1985:78), porque en él se reflejan las emociones.

Tristeza del corazón que quita el hambre, que provoca enfermedad, desgano, ganas de llorar. Tristeza del corazón cuando no hay noticias del ausente, cuando no hay cartas, ni llamadas telefónicas, cuando los sueños no informan cómo está el ser querido.

La mejor forma de procurar el alivio es, al decir de doña Teresa, curandera de Huejutla, Hidalgo, mezclar cempazúchil junto con mohuite y al- 
bahaca. Es un remedio para la tristeza del corazón, y para prepararlo se frotan las hierbas, se ponen a hervir para preparar la infusión, se cuela y ya lista se toma como agua a temperatura ambiente y se frota a la persona con alcohol. "Si te alcanza la tristeza tienes que hacer un novenario, para que te puedas recuperar" (Doña Juanita, comunicación personal, 2003).

La expresión lingüística, tristeza del corazón, que da cuenta del estado de ánimo que provoca la emigración, y las acciones encaminadas a restaurar el equilibrio físico son formas simbólicas que operan en circunstancias socioculturales particulares como es el caso de poblaciones que expulsan mano de obra; las usan y comprenden los sujetos que a su vez las recibieron de sus padres, tal vez para dar cuenta de otras situaciones que provocaban tales emociones y para las cuales había que buscar el remedio.

Y así como siempre habrá situaciones que hacen aflorar las emociones provocando la enfermedad, de la misma manera perpetuamente estarán presentes los sucesos violentos que irrumpen y transforman la vida de los individuos, como es el caso de los accidentes automovilísticos en la actualidad.

Los emigrantes dejan sus pueblos y por carretera llegan a sus lugares de destino. Pero la carretera además de ser el medio que los aleja de sus familias, es también motivo de preocupación por la cantidad y frecuencia con la que ocurren los percances. Por ello, los que se quedan buscan la manera de proteger a los que emprenden la marcha. Así, de acuerdo a lo observado por Arcadia Castillo (2001), doña Juanita curandera de Tepetzintla, Veracruz, era la encargada de llevar a cabo el ritual de protección de carretera. Cuando le solicitaban el servicio, lo hacía en su casa, frente al altar, formando un semicírculo y colocando al centro una gran olla de peltre con un guisado de pollo en salsa roja. Dos canastos con tortillas, rodeados con botellas de refresco, cerveza y aguardiente completaban la ofrenda. El círculo lo delimitaba con siete platos de comida, siete vasos o tazas y cigarros encendidos, y junto a cada plato, una veladora ${ }^{49} \mathrm{de}$ color blanco en vaso de vidrio. Frente al altar, tres velas de cera de colmena: una dentro de un recipiente de vidrio, otra enterrada en la tierra encendida y otra acostada.

El ritual lo iniciaba pidiendo a los asistentes que se sentaran; con una botella de aguardiente iniciaba un recorrido por el semicírculo, y mientras vaciaba el preciado líquido sobre la tierra pronunciaba unas oraciones. Al terminarlas, empezaba a repartir lo ofrendado a todos los presentes, principalmente a los solicitantes del ritual. El rito terminaba al depositar los presentes sus platos vacíos, con los huesos y cueritos, en el lugar de donde lo habían tomado. Con aguardiente volvía a regar la tierra, agradeciendo a los solicitantes el haberles hecho partícipes de dicha ofrenda.

La eficacia simbólica de la curación es tal que entre los nahuas de la Esperanza, Veracruz, "los curanderos se desplazan de su comunidad de origen a los barrios de los emigrantes de su pueblo al norte (en el caso de México) y también organizan en la comunidad ritos curativos que se transmiten en vivo por teléfono al emigrante que necesite la curación" (Ariel de Vidas, comunicación personal, 2005).

En este sentido, las expresiones lingüísticas, como son las oraciones, las acciones efectuadas en el ritual, los elementos, las actitudes son formas simbólicas que se eternizan ante lo que siempre puede suceder y, por ello, en las culturas que se expresan en la Huaxteca, siempre habrá necesidad de buscar estrategias de protección, que como los rituales y la medicina "tradicional" se convierten en el medio principal a través del cual la noción indígena de persona se relaciona con su ámbito, permitiendo la restauración de su equilibrio físicoemocional.

\section{(d) Activando el mundo simbólico para lograr el regreso}

En San Francisco, Huazalingo, en el estado de Hidalgo la emigración también es un factor importante de movilidad geográfica, económica y social. De la misma forma, al igual que en otros lugares, la salida de los jóvenes a la ciudad de Pachuca, a la de México y a los Estados Unidos, es motivo de preocupación para sus mil doscientos habitantes.

Para los emigrantes, como bien señala Samyn (2001:363), las ciudades destino constituyen los límites de un nuevo universo territorial que, como puntos apartados, se unen con su pueblo por medio de líneas rectas en dos direcciones. Por su parte, para los que se quedan, los nombres de estos sitios son incorporados a su universo figurativo impregnados de una fuerte carga emocional; aun- 
que la representación concreta que de tales lugares se hacen, permanezca vaga.

Los emigrantes salen siempre en forma individual, arropados por la oscuridad de la noche. Las madres y/o esposas se quedan con el temor de que el que se va, ya no regresará, por ello, dejan de barrer la casa tres días después de la salida de un familiar "para que regrese" (Samyn 2001:456).

Dejar de barrer para que el emigrante regrese es una acción que cobra sentido, si nos adentramos al mundo simbólico del espacio, los objetos y las acciones. Tal es el caso de la vivienda, la escoba y el barrer ${ }^{50}$. La escoba, de acuerdo a Samyn, es un instrumento indispensable para el hogar. Recostada sobre la pared, dentro o fuera, pareciera ser fiel guardián de la entrada de la casa, pero su significado protector es más obvio, cuando la gente la utiliza para cerrar por fuera una casa momentáneamente vacía ${ }^{51}$. La escoba, siempre puesta en forma contigua a la puerta de la vivienda, es el instrumento que permite a la mujer ${ }^{52}$, mediante la acción de barrer, expulsar los elementos no deseados en el patio de la habitación. Se barre hacia fuera, esparciendo el polvo por la puerta lo más alejado que se pueda o por las orillas del patio. Por ello, si la acción de barrer tiene la intencionalidad de alejar, de expulsar lo que se considera indeseable, dejar de hacerlo conlleva también un propósito, permitir que lo que salió regrese y se reincorpore a su ámbito familiar.

\section{Las Formas Simbólicas y la Antropología a la Luz de la Emigración}

A lo largo de este texto, pretendí dar cuenta de diversos ejemplos y casos de poblaciones de origen teenek y nahua, que en la Huaxteca viven los efectos de la emigración; poblaciones que despliegan su universo cultural y simbólico para hacer frente a este fenómeno dando nueva vida y vigor a sus creencias y prácticas culturales.

Por ello, consideré importante recurrir al concepto de formas simbólicas, considerando que éstas se construyen, heredan, reciclan y transmiten en un contexto social y espacial; que son activadas, adaptadas a nuevas situaciones, e incluso inventadas para evitar que las comunidades sucumban frente a los procesos de cambio y las coerciones que provoca la globalización. No obstante, el utili- zar las formas simbólicas para explicar la manera en que las poblaciones enfrentan culturalmente la emigración y promueven ideológicamente la cohesión interna de las poblaciones, fue sólo un recurso teórico-metodológico que pretende sugerir otras formas de aproximarnos a la inevitable migración.

Considero finalmente que si bien es cierto que nos enfrentamos a un movimiento de globalización ante el cual surge una diversidad de experiencias sociales, políticas y culturales, también lo es la necesidad de buscar una epistemología adecuada para explicarla. La cultura y la ideología han sido temas privilegiados de la antropología, pero desafortunadamente en el estudio de las migraciones no se les ha dado la importancia que merecen, toda vez que se ha priorizado el enfoque económico y político. De la misma forma, las investigaciones sobre la migración dan particular importancia a las condiciones de los emigrantes en el lugar destino y su relación con la comunidad de origen. Por ello, considero necesario investigar qué sucede con las comunidades expulsoras de mano de obra y para ello considero importante enfocarnos al estudio de las formas simbólicas, en el plano de la cultura, y el uso que de ellas se hace, a nivel de la ideología. Juzgo conveniente para construir esa epistemología seguir rastreando las tradicionales herramientas teórico-metodológicas de la antropología, explayadas en los estudios clásicos del parentesco, de la territorialidad, de la organización social, de la relación que establecen los hombres con la naturaleza y con lo sobrenatural, como ya lo han hecho varios antropólogos, para combinar este saber con otras formas de construir el conocimiento. Lo propio y lo que aportan otras disciplinas pueden conjugarse para conformar una estrategia de producción de conocimiento sobre la migración y sus múltiples aspectos.

Agradecimientos: A los pobladores de la Huaxteca que me abrieron sus puertas y compartieron conmigo el dolor que provoca ver partir al esposo, a un hijo o a cualquier familiar. Gracias también al Instituto de Investigaciones Antropológicas de la Universidad Nacional Autónoma de México por apoyar las investigaciones de su personal. De la misma manera agradezco a los evaluadores de este trabajo, porque su minuciosa lectura me permitió mejorar este texto. 


\section{Referencias Citadas}

Alcorn, J.B.

1984 Huastec Mayan Ethnobotany. University of Texas, Austin.

Ariel de Vidas, A.

2003 El Trueno ya no Vive Aquí. Representación de la Marginalidad y Construcción de la Identidad Teenek (Huasteca Veracruzana, México). CIESAS-Colegio de San LuisCentro Francés de Estudios Mexicanos y Centroamericanos-Instituto de Investigaciones para el Desarrollo, Colección Huasteca, México.

1993 Prácticas familiares en la Huasteca Veracruzana: algunas aportaciones contemporáneas al estudio del parentesco huasteco. Cuadrante 11-12:53-83.

Aragonés, A.M.

2006 Migración: otro saldo negativo del foxismo. La Jorna$d a, 28$ de noviembre, D.F., México

Arizpe, L.

1975 Indígenas en la Ciudad de México. El caso de las "Marías”. México, Sepsetentas.

Ávila Méndez, A., B. Barthas y A. Cervantes

1995 Los huastecos de San Luis Potosí. En Región Oriental, editado por Gabriela Robledo Hernández, pp. 57-59. INI/ SEDESOL. Col. Etnografía Contemporánea de los Pueblos Indígenas de México, México.

Barabas, M.A.

2003 Introducción: una mirada etnográfica sobre los territorios simbólicos indígenas. En Diálogos con el Territorio. Simbolizaciones sobre el Espacio en las Culturas Indígenas de México, coordinado por A.M. Barabas, pp. 13-36. INAH, México

Barón Larios, J.

1994 Tradiciones, Cuentos y Creencias Nahuas. Gobierno del Estado de Hidalgo-Consejo Estatal para la Cultura y Las Artes de Hidalgo, México.

Blanco, C.

2006 Introducción. Movilidad creciente y emergencia de nuevos enfoques migratorios. Migraciones. En Nuevas Modalidades en un Mundo en Movimiento, editado por C. Blanco, pp. 11-32. ANTROPOS, España.

Briseño Guerrero, J.

1988 La Organización Comunal y la Lucha por la Tierra. CIESAS, México.

1994 ¿Cuántos más Muertos Quieren? CIESAS, México.

Casimires, D.

1979 La cultura campesina tradicional. En Campesinos y Sociedades Campesinas. Selección de Teodor Shanin, pp. 249267. Fondo de Cultura Económica, México.

Castillo Gómez, A.

2001 El zacahuil y los zacahuileros de Tepetzintla: una historia sagrada y profana. Ponencia presentada en el XXVI Mesa Redonda de la Sociedad Mexicana de Antropología, Zacatecas.

\section{CONAPO}

2000 Índice de Marginación Municipal. Secretaría de Gobernación, México.

Esteva, G.

2003 El vaivén de las ilusiones y realidades. En Sin maíz, No hay País, coordinado por G. Esteva y C. Marielle, pp. 177218. CONACULTA-Museo Nacional de Culturas Populares, México.
Ferrer Argote, L.F.

1983 Producción y Reproducción en una Comunidad Indígena de la Huasteca Potosina. Tesis para optar por el grado de Maestro, Escuela Nacional de Antropología e Historia, México.

Geertz, C.

1991 La Interpretación de las Culturas. Gedisa editorial, México.

González, H. y V. Gavilán

1993 Cultura e identidad étnica entre los aymaras chilenos. Chungara 24/25:145-158.

Gupta, A. y J. Ferguson

1992 Beyond 'cultura': Space, identity, and the politics of difference. En Cultural Anthropology, editado por J. Ferguson y A. Gupta, vol. 7, núm. 1, pp. 7-23. The American Anthropological Association, USA.

Hanners, U.

1993 The cultural rol of world cities. En Humaninisig the City?, editado por C.A.P. Fukuj, pp. 67-81. Edimburg University Press, Edimburgo.

Kearney, M.

1996 Reconceptualizing the Peasantry, Anthropology in Global Perspective. Westview Press, A Division of Harper Collins Publishers, University of California Riverside.

López Austin, A.

1980 Cuerpo Humano e Ideología: las Concepciones de los Antiguos Nahuas, 2 vols., UNAM, México.

Laughin, R.M.

1964 The Huastec. En Handbook of Middle American Indians Vol. VII, editado por Middle American Research Institute, pp. 298-310. Tulane University, New Orleans.

Leyva, M.

2003 El éxodo de los veracruzanos a los Estados Unidos. Noreste Diario Regional Independiente, 15 de septiembre, Tuxpan, Veracruz, México.

Lomnitz, C.

1995 Las Salidas del Laberinto. Cultura e Ideología en el Espacio Nacional Mexicano. Joaquín Mortiz-Planeta, México.

Pérez Castro, A.B.

1991 Lázaro Cárdenas, Michoacán: donde se funden la residencia y el olvido. En La Identidad: Imaginación, Recursos y Olvidos, editado por A.B. Pérez Castro, pp. 53-65. IIA-UNAM, México.

Pérez-Ruiz, M.L.

2002 Del comunalismo a las megaciudades: el nuevo rostro de los indígenas urbanos. En La Antropología Sociocultural en el México del Milenio. Búsquedas, Encuentros y Transiciones, coordinado por G. de la Peña y L. Vázquez León, pp. 295-340. Biblioteca Mexicana, Instituto Indigenista, Consejo Nacional para la Cultura y las Artes, Fondo de Cultura Económica, México.

Puig, $\mathrm{H}$.

1976 Vegetation de la Huasteca. Misión Archéologique et Ethnologique Francaise au Mexique, México.

Rivermar Pérez, M.L.

2005 "Uno va Agarrando otras Culturas sin Soltar la Nuestra”. Migración Internacional e Identidad Étnica y Cultural en una Comunidad Nahua del Estado de Puebla, Tesis 
para optar al grado de Doctor en Antropología, Facultad de Filosofía y Letras/Instituto de Investigaciones Antropológicas, UNAM, México.

Rouse, R.

1991 Mexican migration and the social space of postmodernism. Diáspora 1:8-23.

Sandstrom, A.R.

1991 Corn is our Blood. Culture and Ethnic Identity in a Contemporany Aztec Indian Village. Col. The Civilization of the American Indian Series, 206. University of Oklahoma Press, Norman and London.

Samyn, G.

2001 San Francisco, Pueblo Nahua en la Huasteca. Un análisis del Simbolismo de la División del Espacio. Tesis Doctoral, Facultad de Filosofía y Letras/Instituto de Investigaciones Antropológicas, UNAM, México.

Sánchez, M.J.

1995 Comunidad sin Límites. Un Estudio sobre la Reproducción de la Identidad Étnica de Migrantes Zapotecas Asentados en el Área Metropolitana de la Ciudad de México. Tesis para optar por el grado de Doctor en Sociología, Colegio de México, México.

SEDESOL

2005 Cálculos Propios a Partir de los Tabulados del XII Censo General de Población y Vivienda, México.

Serrano Carreto, E., A. Embriz Osorio y P. Fernández Ham 2002 Indicadores Socioeconómicos de los Pueblos Indíge- nas de México. Instituto Nacional Indigenista, -UNDP México-CONAPO, México.

Tapia de Zenteno, C.

1985 [1767] Paradigma Apologético y Noticia de la Lengua Huaxteca, editado por R. Acuña. UNAM, México.

Thompson, J.B.

1993 Ideología y Cultura Moderna. Teoría Crítica Social en la Era de la Comunicación de Masas. Traducido por G. Fantinati Caviedes. Universidad Autónoma MetropolitanaXochimilco, México.

Valle, J.

2003 Reciprocidad, jerarquía y comunidad en la tierra del trueno (la Huasteca). En La Comunidad sin Límites. Estructura Social y la Organización Comunitaria en las Regiones Indígenas de México, coordinado por S. Millán y J. Valle, pp. 211-340. Colección Etnografía de los Pueblos Indígenas de México, INAH, México.

van Dijk, T.A.

2000 Ideología. Una Aproximación Multidisciplinaria. Traducido por L. Berrone de Blanco. Gedisa editorial, Barcelona.

Warman, A.

2002 El Campo Mexicano en el Siglo XX. Fondo de Cultura Económica, Sección de Obras de Historia, México.

Zorn, E.

1998 (Re)Fashioning the self: Dress, economy, and identity among the Sakaka of Northern Potosí, Bolivia. Chungara 30:161-196.

Notas

1 El concepto de activar tiene también la connotación de avivar y es en este sentido que lo utilizo, para referirme a la forma en que las poblaciones avivan, dan nueva vida y vigor a sus creencias y prácticas culturales para enfrentar un fenómeno, como es la migración.

2 Para el autor, el concepto "Cultura de la pobreza" era aplicable a las poblaciones que vivían en condiciones de subempleo y desempleo, marginación, hacinamiento y promiscuidad que vivían en la Ciudad de México.

3 Martha Judith Sánchez (1995) identifica tres enfoques teóricos dominantes en estos estudios: el enfoque funcionalista cuyo interés se basa en la adaptación de los migrantes a sus nuevos entornos; el histórico estructural en donde se analiza la migración como un fenómeno dependiente de un contexto económico nacional y mundial; y el enfoque que se interroga sobre los procesos de constitución o pérdida de la identidad de los emigrantes

4 Sobre los enfoques, teorías y paradigmas que se emplean para dar cuenta de la migración pueden verse los trabajos de Maya Lorena Pérez-Ruiz (2002) y el de Ana Bella Pérez Castro (1991), que considero complementarios en la información vertida. En el primero se hace un recuento de las investigaciones antropológicas sobre la migración; el segundo anota varios trabajos que, desde la sociología, estudian también al tema.

5 Para mayor información remito al lector al trabajo de Cristina Blanco (2006) "Movilidad creciente y emergencia de nuevos enfoques migratorios en Migraciones. Nuevas movilidades en un mundo en movimiento.
6 Para la región Centro Sur Andina se puede citar, entre otros, los estudios de González y Gavilán (1993) y Zorn (1998).

7 Para mayor información puede consultarse el trabajo de Rivermar Pérez (2005).

8 La historia del concepto de ideología surge a finales del siglo XVIII con el filósofo francés Destutt de Tracy, ya que fue el primero en usarlo al considerar que no se podía conocer las cosas por sí mismas, sino sólo las ideas formadas a partir de las sensaciones que tenemos de ellas. Literalmente se refirió a la ideología como "ciencia de las ideas" considerando que ésta habría de ser positiva, útil y capaz de una rigurosa exactitud. Sin embargo, ya para el siglo XIX, como resultado de la introducción del término en la arena política, su sentido comenzó a cambiar. De tal forma que como señala John B. Thompson, "La ideología como ciencia positiva y superior, digna del más alto respeto, poco a poco cedió el paso a una ideología como ideas abstractas e ilusorias, sólo digna de burlas y desdén" (Thompson 1993:35). Thompson realiza una historia detallada del concepto ideología y de la forma en que diversos autores retomaron el concepto como un sistema de representaciones que sirve para mantener relaciones sociales de dominación. No obstante intentar darle otro sentido al término, considera que lo ideológico está relacionado con el establecer y sostener las relaciones de dominación. Por su parte, Teun A. van Dijk (2000) presenta una reflexión sobre el concepto, por la cual, remito al lector interesado a sus obras.

9 Se compra el ganado indobrasil porque es el que más resiste las condiciones climáticas de los trópicos bajos húmedos. 
10 De acuerdo a la información proporcionada por Ana María Aragonés, retomando los datos del economista José Luis Calva, el salario real del campo fue descendiendo y para 2002 había perdido 52 por ciento de su poder adquisitivo, por lo que el número de pobres en el ámbito rural pasó de 22 millones 139 mil 967 a 828 mil 638, entre 2004 y 2005 (Aragonés, La Jornada, 25 de noviembre de 2006). En relación a la situación de la Huaxteca, desde tiempo atrás la situación de pobreza era evidente, ya que de acuerdo a la información proporcionada por Claudio Lomnitz (1995) en su libro Las Salidas del Laberinto, para fines del siglo pasado, en la Potosina el salario rural diario era menos de una tercera parte del que se pagaba en la Ciudad de México. De la misma manera informa que en 1985 los comerciantes mestizos compraban el kilo de piloncillo (azúcar en forma de cono) a los indios a 4 dólares el kilo y lo vendían a los intermediarios a 4,10. En otra información comenta que un ranchero, la clase alta de la región, se jugó 40.000 dólares en un fin de semana, lo que era más de veinte meses de salario de un peón. Por su parte, el Diario la Jornada en un artículo basado en datos obtenidos por investigadores del Instituto Nacional de la Nutrición "Salvador Zurbarán”, publicado el 26 de junio de 2005 publicó en su sección dominical "El mapa del hambre en México", donde se alude que dentro de las regiones críticas está la Sierra Madre Oriental, asiento de teenek y nahuas. Finalmente cabe citar la información proporcionada Consejo Nacional de Población (CONAPO) y la Secretaría de Desarrollo Social y Humano (SEDESOL) relativa que señala que de los 37 municipios que integran la Huaxteca Veracruzana y la Hidalguense, el $51 \%$ está clasificado como de alta marginación y el $49 \%$ como de muy alta marginación. Para tal clasificación, los indicadores que se tomaron arrojaron que aproximadamente el $40 \%$ de la población de 15 años y más es analfabeta y el $55 \%$ no cuenta con la primaria completa. Alrededor del $16 \%$ de las viviendas de sus habitantes no tiene drenaje ni servicio sanitario, el $25 \%$ no cuenta con energía eléctrica, cerca del $50 \%$ no tiene agua entubada y poco más o menos del $52 \%$ son viviendas con piso de tierra. El 85\% de la población ocupada recibe ingreso de hasta 2 salarios mínimos, lo que es equivalente a alrededor de 5 dólares diarios (CONAPO 2000 y SEDESOL 2000).

11 Campesino nahua de Huejutla, Hidalgo. Entrevista realizada el 15 de agosto de 2004.

12 De acuerdo a don Juan, les pagaban en pesos mexicanos lo que es el equivalente a 6 dólares americanos por jornada, mientras que en donde vivían apenas se les daban 2 dólares. El mismo informante mencionó que les depositaban un enganche de 50 o 60 dólares para cubrir temporadas de 3 meses y que solicitaban cerca de 400 gentes mayores para trabajar. Asegura que los recogían en Huejutla, Tantoyuca y Tamazunchale.

13 Años atrás, Edmundo Flores también asediaba al presidente López Potillo con los datos de países que, como Estados Unidos, lograban que con sólo el $2 \%$ de la población ocupada en el campo se lograba la producción de alimentos y aun la exportación de los mismos (Esteva 2003:205).

14 La máxima norma que rige a todos los mexicanos es la Constitución Política de los Estados Mexicanos de 1910. En ella se contemplaba en su artículo 27 la posibilidad de que los pueblos indígenas y los campesinos tuvieran acce- so a la tierra. A los pueblos indígenas, vía la restitución, se les reconocían sus tierras comunales desde tiempos antiguos; a los campesinos se les dotaba a través del reparto agrario. Sin embargo, para 1992, y de acuerdo a los cambios que el presidente Carlos Salinas de Gortari propuso a dicho artículo, se canceló la posibilidad de que los indígenas pudieran tener tierra. Publicado en el Diario Oficial de la Federación el 6 de enero de 1992, la Fracción VII en su segundo párrafo, dice textualmente: "La ley protegerá la integridad de las tierras de los pueblos indígenas", sin embargo, se derogaron las fracciones de la X a la XIV que eran las que establecían el derecho a la restitución y dotación de tierras y el procedimiento para lograrlo por parte de los núcleos de población ejidal o comunal.

15 En este sentido, México entró al Tratado de Libre Comercio de América del Norte (TLCAN) en 1994, como un comprador de alimentos básicos, vendedor de mano de obra barata y proveedor marginal de productos tropicales.

16 Otros puntos de cruce son: Tijuana, Ciudad Juárez, Nuevo Laredo y Piedras Negras.

17 Porcentaje que pudiera parecer pequeño en relación al 30\% que procede de los estados de mayor tradición migratoria, como son Zacatecas, Aguascalientes, Guanajuato, Michoacán y Jalisco, pero hay que remarcar que mientras que en estos estados, la tradición de emigrar se remite a principios del siglo pasado, en la Huaxteca el movimiento es reciente y amenaza con continuar.

18 Entre los factores que la han provocado pueden señalarse: (1) La insuficiencia dinámica de la economía nacional para absorber el excedente de fuerza de trabajo, (2) La demanda de mano de obra mexicana en los sectores agrícolas, industrial y de servicios de USA, (3) El considerable diferencial salarial entre ambas economías, (4) La tradición migratoria hacia el vecino país, y (5) la operación de complejas redes sociales y familiares que vinculan los lugares de origen y destino, las cuales facilitan la experiencia migratoria.

19 Los aliens se consideran hoy en día como la causa de la peor de las calamidades que aflige al país, como el narcotráfico. Sin embargo, el narcotráfico está dentro, California es autosuficiente en la producción de crack y marihuana. San Diego es la capital de las anfetaminas y suena risible pensar que los emigrantes que salen de las comunidades indígenas lleven la droga caminando, cuando es bien sabido por las noticias televisivas y de la prensa que los traficantes de droga cuentan con toda una infraestructura en transportes (aviones, barcos, camiones y autos), vías de comunicación (rutas construidas por tierra y mar) y armamento moderno para introducirla en la Unión Americana. Las percepciones negativas que se tienen sobre los emigrantes se acentúan cuando hay recesión económica, pero cuando hay expansión económica se llega a reconocerlos como muy trabajadores.

20 La Secretaría del Trabajo y Previsión Social aceptó revisar las quejas de la CIOAC (Central Independiente de Obreros Agrícolas y Campesinos) y de la Organization Farmworker Justice Fund contra el Gobierno de los Estados Unidos que argumentan que esa nación no cumple la legislación laboral con los trabajadores agrícolas que tienen visa, pues desconoce beneficios como el pago de horas extras, servicios de vivienda, seguridad y salud, a los que tienen dere- 
cho los mexicanos., indemnización por lesiones y a no ser discriminado.

21 Periodista del Diario de Tuxpan que realizó una entrevista a un grupo de pescadores reunidos en el puerto de Tuxpan en el mes de septiembre de 2003.

22 San Chárbel Majluf (1828-1898) fue un ermitaño del rito maronita y primer santo oriental canonizado por la Sede Apostólica desde el siglo XIII. Se dice que numerosas de sus imágenes milagrosamente exudan aceite el cual se utiliza en la oración por los enfermos. Además de ser bien conocido en el Medio Oriente y en toda la Iglesia, en América es particularmente venerado en México a partir de la inmigración maronita que comenzó en el siglo XIX. Su devoción se propaga en la actualidad muy rápido por el aumento de milagros. En este sentido, en Tantoyuca, Veracruz, el santo es venerado y se le hacen diversas peticiones a través de listones. El color del listón es de acuerdo a la petición y casi en todos los que son de color blanco se encuentran escritas peticiones solicitando la protección de algún ser querido.

23 Mezcla de lodo y zacate.

24 El XI censo de población y Vivienda para 1990 (INEGI, Instituto Nacional de Estadística, Geografía e Informática) registró que en Matamoros, Tamaulipas se registraron 1315 hablantes de lenguas indígenas, de los cuales 505 eran hablantes de nahuatl, 188 de huaxteco y 146 de totonaca.

25 Como lo registra Ariel de Vidas (2003) para los teenek de Loma Larga.

26 Como lo dejó plasmado Sandstrom (1991) para los nahuas de Amatlán.

27 La endogamia absoluta de los grupos, sobre todo entre los teenek, fue tenida por verdad indiscutible. En este sentido, Laughlin (1964:306) aseguró que el matrimonio con mestizos se consideraba repugnante. Años más tarde, Ávila et al. (1995) destacaron la presencia de uniones interétnicas en el municipio de Tancanhuitz, San Luis de Potosí y Ferrer Argote (1983) destacó las uniones entre indígenas y mestizos al norte de Aquismón, San Luis de Potosí.

28 El llamado "precio de la novia" estaba acorde con su posición social. En este sentido, el padre de la novia aceptaba o rechazaba lo que un solicitante ofrecía por casarse con su hija.

29 Ceremonias que han sido registradas por Barón Larios (1994:28-29).

30 En el caso de los teenek de Loma Larga, Ariel de Vidas (1993:63-64) apunta que todavía se hacen regalos considerables de comida, bebida y otros presentes a la familia de la novia.

31 Retomo de Casimires (1979:250) su idea de que la cultura campesina tradicional puede entenderse por "los contenidos y los valores culturales que se transmiten oralmente".

32 Radio Veracruzana cuenta con una programación dominical que permite el enlace entre emigrantes y población local. De la misma forma, en cada localidad existe por lo menos un café Internet en el que los alumnos de secundaria o de Escuelas Técnicas mandan mensajes o chatean con los familiares emigrantes.

33 Sea porque viven en la frontera o en algún estado de la República, o bien aquellos cuya estancia en los Estados Unidos está regularizada y pueden entrar y salir del país vecino sin mayor problema.
34 Tomo en este sentido las ideas de Barabas (2003).

35 En este texto, Thompson (1993) propone una concepción estructural de la cultura, que a la vez que enfatiza el carácter simbólico de los fenómenos culturales hace referencia al contexto sociohistórico. Parcialmente de acuerdo con Geertz (1991), pone énfasis en lo que éste no prestó atención, en las relaciones sociales estructuradas dentro de las cuales se insertan siempre los símbolos y las acciones simbólicas.

36 Tabla donde se anotan principalmente los lugares a los que se hace referencia en este trabajo.

37 Como en los años setenta Arizpe (1975) lo hizo en su trabajo sobre indígenas en la Ciudad de México.

38 Ferrer Argote (1983:3-5) señala que en una unidad doméstica donde hay varios hombres adultos, una parte de ellos sale a trabajar fuera y la otra se queda en su interior; por su parte, Briseño Guerrero (1994:43) indica que los futuros emigrantes se eligen de acuerdo a la división del trabajo dentro de la unidad productiva.

39 Las faenas sirven para arreglar los caminos, las escuelas públicas o la iglesia; trabajo comunal que si bien es cierto que repercute en beneficio de la comunidad, también es verdad que el mayor provecho es para el Estado que debería emplear los impuestos en la construcción de obras educativas y de infraestructura; responde también en ventajas para los comerciantes e industriales que aprovechan tales caminos y en el beneficio de las autoridades eclesiásticas.

40 Esta connotación se aprecia más claramente en el apartado (b) Castigo y curación: activando el mundo simbólico para enfrentar la emigración.

41 La legitimidad para Thompson (1993) se expresa en ciertas formas simbólicas. Thompson (1993:67) considera que Weber distinguió tres tipos de bases sobre las que se pueden sustentar las declaraciones de legitimidad, bases racionales (que apelan a la legalidad de las reglas sancionadas), bases tradicionales (que apelan a la inviolabilidad de las tradiciones inmemoriales) y bases carismáticas que apelan al carácter excepcional de una persona que ejerce la autoridad).

42 En el transcurso de su vida, los hombres van acumulando obligaciones y con ello, aumentan sus derechos sobre las propiedades de la comunidad y de la tierra que ésta le asigna para su usufructo (Briseño 1988:24). Por su parte, Ferrer (1983:6-13) apunta que en San Pedro de las Anonas, en Aquismón, “... Todos los hombres casados y con residencia propia tienen el deber de participar en las faenas semanales".

43 Ariel de Vidas (2003) alude a que en Loma Larga, la comunidad decidió repartir las tierras de un hombre que abandonó su predio y en diez años no dio señales de vida. Se las dieron a familias de la ranchería de Tototla que habían sido expulsadas de sus tierras en el marco de un litigio de tierras. En otro caso, en la comunidad de Corral Viejo de la comunidad de la Laja al norte de Tantoyuca, pese que el emigrante enviaba dinero cada año para cumplir con su obligación de las faenas, los jóvenes locales, a través de las autoridades agrarias nacionales, lograron quedarse con sus tierras. En este sentido, para la autora, "Con el fin de tener acceso a los bienes comunales es, pues, necesario acumular dos tipos de derecho estrechamente ligados: el del acceso a la tierra, asociado al principio de residencia efecti- 
va, y el derecho de la persona, fundado sobre el principio de filiación." (Ariel de Vidas 2003:169-170). Por su parte, Valle (2003:260) apunta que en el caso de los que emigran hay dos argumentos recurrentes para reclamar su separación: que no hacen faena y "que no le dan de comer a los cerros".

44 Entrevistas a doña Lupita, don Francisco y Julia de la población de Huejutla. En Tancoco, también don Pedro, doña Goyita, y don Luis coinciden con esta apreciación.

45 Para una mayor información, consúltense los trabajos de Esteva (2003) y Warman (2002).

46 Si bien Thompson (1993) ofrece una tabla de modos de operar de la ideología y algunas estrategias típicas de la operación simbólica, considero que uno puede jugar con otras. Por ello, considero que bien puedo llamar estrategias vengativas y estrategias de dependencia a las acciones ideológicas cuya intencionalidad es causar miedo a los que quisieran olvidarse de sus costumbres. Intencionalidades que buscan la unidad del grupo étnico.
47 D'hipaak, deidad del maíz entre los huaxtecos.

48 Tamal de gran tamaño hecho con maíz martajado, chile y carne.

49 Trozo cilíndrico de parafina con un pabilo en el centro.

50 Información obtenida del excelente trabajo de tesis realizado por Samyn (2001).

51 "Tanto como un rechazo de tener animales dentro de la casa en ausencia de los habitantes, la escoba descarta la entrada subrepticia de todos los visitantes, hasta de las personas que en otras ocasiones entran de manera maquinal. Obviamente, la escoba no sustituye el candado. Cualquier individuo bien o malintencionado puede desbaratar el armazón sin mayor problema. Sólo logra obtener cierto poder de exclusión por su carga simbólica." (Samyn 2001:240).

52 "Por otra parte, las mujeres que barren poco, no tienen buena reputación en el pueblo. Se cree que en los alrededores de su vivienda, especialmente en la parte de atrás, se facilita la entrada a los malos espíritus." (Samyn 2001:242). 